\title{
Mirada, vanitas y desengaño en la representación de la mujer en tres sonetos de Quevedo
}

\author{
María Cristina QuinTERo \\ Bryn Mawr College
}

\begin{abstract}
Utilizando como marco temático un poema de Sor Juana Inés de la Cruz, este artículo explora la relación palabra-imagen en la presentación negativa del cuerpo femenino en tres sonetos de Francisco de Quevedo. Acudiendo además a las categorías de vanitas y desengaño, especialmente con relación a la mirada, se analiza cómo los dos poetas desarrollan una preocupación sobre los límites de toda representación artística, tanto verbal como visual.
\end{abstract}

Keywords: Quevedo, desengaño, vanitas, palabra-imagen, Sor Juana.

\begin{abstract}
Este, que ves, engaño colorido que del arte ostentando los primores, con falsos silogismos de colores es cauteloso engaño del sentido; éste, en quien la lisonja ha pretendido excusar de los años los horrores, y venciendo del tiempo los rigores, triunfar de la vejez y del olvido, es un vano artificio del cuidado, es una flor al viento delicada, es un resguardo inútil para el hado: es una necia diligencia errada, es un afán caduco y, bien mirado, es cadáver, es polvo, es sombra, es nada.
\end{abstract}

Sor Juana Inés de la Cruz

El famoso soneto de Sor Juana Inés de la Cruz representa una de las más notables meditaciones sobre la relación palabra-imagen en el siglo XVII ${ }^{1}$. Aparentemente inspirado en un retrato que se pintó de la célebre poeta, éste es un poema que ha sido frecuentemente -aunque inexactamente- caracterizado como ecfrástico. Es un texto que, sin embargo, sí aborda directamente la problemática implícita en toda representación artística, sea verbal

I El soneto ha sido estudiado, entre otros, por William Clamurro (I986), Georgina Sabat de Rivers (1992), Emilie Bergmann (1992), Betty Sasaki (1997) y Luis Avilés (2000). 
o visual; y es, por lo tanto, un texto que nos ayuda a enmarcar una discusión del intercambio entre pintura y poesía que ocupa este volumen. Desde un principio, con el uso del verbo «ves» y la invitación a un «tú» indeterminado a observar el retrato, el poema propone una experiencia visual a sus lectores. Interesantemente, como muy bien ha señalado Luis Avilés (2000), en ningún momento se nos da una descripción detallada del retrato en sí, por lo tanto se rechaza la esperada dimensión ecfrástica implícita en la invitación. A la vez, emplea vocablos relacionadas con la pintura -colores, arte, artificio-y el interlocutor se ve obligado a ponderar imaginativamente el retrato ausente. Éste ha sido sustituido con un comentario moral y amargo sobre la ineficacia de la pintura y, por ende, de toda labor artística. Este anti-retrato (como lo caracteriza Betty Sasaki) sintetiza lo verbal y lo plástico y nos comunica, a través del uso insistente de palabras como engaño, falso, horrores, rigores, vejez, y olvido, que el cuadro es una falsificación, una tergiversación de la realidad. Éste es un soneto de desengaño existencial y artístico, y los versos nos llevan inexorablemente al mensaje moral del último verso, calcado a su vez sobre otro verso famoso gongorino: el retrato es «cadáver, polvo, sombra, nada». El hecho de que la autora cite de una manera tan autoconsciente a Luis de Góngora, uno de sus antecedentes poéticos más importantes, le permite inscribirse dentro de una tradición masculina poética, a la vez que critica implícitamente la misoginia que siempre ha caracterizado la representación escopofílica de la mujer por pintores y poetas ${ }^{2}$.

Usando el poema de Sor Juana como marco temático, el tema que me ocupa en estas páginas es el análisis de ciertos textos que han sido precisamente considerados como misóginos pero que contienen inesperadamente la misma preocupación sobre los límites de la representación artística, tanto verbal como visual. Me centraré en tres sonetos de Francisco de Quevedo acudiendo además a dos temas relacionados (y a veces intercambiables): desengaño y vanitas. Estos términos tradicionalmente se han usado en contextos artísticos diferentes: desengaño se refiere a la temática y actitud existencial que llegó a permear todos los géneros literarios de la temprana edad moderna y que hemos visto en el poema de Sor Juana. Vanitas, por su parte, se ha utilizado casi exclusivamente con relación a la pintura, especialmente el género simbólico que comunica el mismo mensaje: la vida es efímera y el mundo ilusorio. Estas dos tradiciones, una literaria y la otra visual, se desarrollaron simultáneamente y llegaron a un auge durante la época del Barroco. En un libro reciente titulado Vanitas. Retórica visual de la Mirada, el historiador de arte Luis Vives-Ferrándiz Sánchez ha opinado que tanto la vanitas como el desengaño en la cultura barroca hispánica tienen que ver con «el

2 No comparto, sin embargo, la interpretación negativa que hace Clamurro (1986) cuando considera que tal inscripción en la tradición por parte de Sor Juana representa un tipo de «self-effacement» o abandono de su propia voz. 
saber mirar» (20II: 33). Más específicamente nos dice que «mirar, verdad, y tiempo son los ejes sobre los cuales se articula el concepto de vanitas y desengaño: mirar para desengañarse, mirar para alcanzar la verdad eliminando las apariencias, mirar para acomodar la vida al ineludible paso del tiempo» (20II: 34). Aunque Vives-Ferrándiz considera estas múltiples funciones de la mirada principalmente con relación a la pintura y otros géneros visuales como emblemas y jeroglíficos, también es posible encontrar estas funciones en la poesía cultivada en el diecisiete; y no solo en la poesía seria de una Sor Juana sino también en sonetos de vena satírico-burlesca como los de Quevedo que propongo examinar aquí.

En efecto, la mirada es una de las características definitivas de la poesía de la época, especialmente la poesía que deriva de la tradición petrarquista; y uno de los objetos privilegiados de esta mirada es precisamente el cuerpo de la mujer, uno que termina convirtiéndose frecuentemente en el locus de un desengaño literario. Son cuantiosos los textos en que el desengaño se manifiesta a través de una representación pesimista de la mujer: su ausencia, su inconstancia, sus debilidades, su vejez o, en última instancia, la descomposición de su cuerpo. Más allá de la lírica, recordemos, por ejemplo, que Dulcinea del Toboso es todo ausencia, el reconocimiento de lo cual lleva al desengaño final y muerte de Don Quijote; o que en el momento culminante de la obra El mágico prodigioso de Calderón de la Barca, cuando Ciprión está a punto de violar a Justina, se encuentra abrazando un esqueleto; o, que escrito en los cuerpos abusados de las protagonistas de María de Zayas, enontramos el mensaje anunciado en el título de sus Desengaños amorosos.

Los poemas de Francisco de Quevedo representan en conjunto un ejemplo particulamente vehemente de cómo el uso de imágenes verbales se convierte en el vehículo para comunicar el tema de desengaño a través del cuerpo de la mujer. Los tres sonetos de Quevedo que he escogido ofrecen la imagen del cuerpo femenino en diferentes etapas de ruina y descomposición; o sea, son poemas que aluden precisamente a aquellos «horrores de los años» que Sor Juana señala en su soneto. Observaremos además cómo el poeta utiliza técnicas o estrategias que realzan la dimensión escópica, incorporando la mirada como uno de los temas principales. En estos tres poemas, una pequeñisima parte de los numerosos que Quevedo dedicó a la descripcion de una mujer, podemos identificar un tipo de progresión o gradación en la manera en que presenta los estragos del tiempo reflejados en el cuerpo femenino: son «sucesivas progresiones de difunta», parafraseando uno de los poemas quevedianos más famosos. En general, la crítica literaria ha caracterizado estos sonetos como ingeniosos ejercicios conceptistas o manifestaciones de la intensa misoginia del poeta. Sin embargo, a través de imágenes y metáforas asociadas con la visualidad, estos textos revelan una dimensión temática sobria: el reconocimiento de lo transitorio de la exis- 
tencia humana, la conciencia del abismo que separa el ser del parecer, y la desesperanza existencial que acompaña tal concienciación. El mensaje resulta muy parecido, entonces, al que encontramos en el soneto de Sor Juana y que se manifiesta repetidamente en la obra moral de Quevedo; como, por ejemplo, en los sonetos metafísicos y sus tratados neo-estóicos.

Empiezo con un soneto bastante conocido y comentado, «Venganza de la edad en hermosura presumida», ya que de muchas maneras sintetiza lo verbal y lo visual de una manera no desemejante a lo que hace Sor Juana. En este poema, el «yo poético» amonesta a la amada Floralba por haber rechazado sus atenciones amorosas en el pasado y se burla despiadadamente del cuerpo envejecido de la dama quien ahora ha dejado de ser deseable.

Cuando tuvo, Floralba, tu hermosura, cuantos ojos te vieron, en cadena, con presunción, de honestidad ajena, los despreció, soberbia, tu locura.

Persuadiote el espejo conjetura de eternidades en la edad serena, y que a su plata el oro en tu melena nunca del tiempo trocaría la usura.

Ves que la que antes eras, sepultada yaces en la que vives; $y$, quejosa, tarde te acusa vanidad burlada.

Mueres doncella, y no de virtuosa, sino de presumida y despreciada: esto eres vieja, esotro fuiste hermosa (I98I: 366).

Este soneto aparece en la cuarta parte -dedicada a la musa Erato-del Parnaso español editado por González de Salas. En esta sección, según el editor, el poeta «canta poesías amorosas, esto es celebración de hermosuras, afectos propios y comunes del amor» (Smith 1987: 3). Esta clasificación resulta sorprendente dado que en el poema, se dramatiza no la belleza de la dama o el amor o el deseo, sino la pérdida y la ausencia de todos éstos. Es un retrato particularmente cínico y desdeñoso de la que antes fue su amada y las imágenes que predominan se relacionan primordialmente con el paso del tiempo, la ruina y la decadencia. Sin embargo, el soneto sigue compartiendo ciertas características típicas del soneto amoroso: en particular, la obsesión con las ópticas del amor y la vigilancia del cuerpo de la mujer, combinadas con una queja amarga de la supuesta crueldad y orgullo de la dama. Críticos como María José Alonso Veloso también lo han asociado con 
el tema renacentista del carpe diem, aunque sería más adecuado designarlo como un soneto post carpe diem ya que aquí el poeta no intenta persuadir a la dama a que goce de su juventud y belleza, entregándose amorosamente al poeta, sino que dramatiza las consecuencias drásticas de no haberlo hecho en el pasado.

El poeta manifiesta una preocupación con visualidad a lo largo del poema, y en esto, el texto cumple con las característica principales de los temas vanitas/desengaño, según Vives-Ferrándiz (20II: 34): la mirada, su asociación con el paso del tiempo y el reconocimiento de la falsedad de las apariencias. Autoconscientemente, el enunciador poético utiliza una óptica retórica, usando imágenes que pretenden ser simultáneamente verbales y visuales. Los dos versos iniciales - «Cuando tuvo, Floralba, tu hermosura,/ cuantos ojos te vieron, en cadena»- aluden precisamente a múltiples «ojos» y anticipan referencias a la mirada a lo largo del poema. En las teorías neoplatónicas, como es bien conocido, la belleza y el amor entran por los ojos; pero en estos versos, la asociación mirada-amor se ubica en el pasado. Los ojos que antes seguían la belleza de la mujer ahora se han reducido a la mirada desdeñosa del yo poético que se auto-dramatiza observando a una mujer quien a su vez se está mirando en un espejo. Como en el soneto de Sor Juana, tenemos aquí una doble representación y re-contextualización de la imagen de la mujer bella que aparece con tanta frecuencia en la poesía amatoria. En particular, el uso de la imagen del espejo alcanza una complejidad casi metafísica (y hasta borgesiana) cuando exclama «persuadiote el espejo conjetura/ de eternidades en la edad serena». El espejo es, como bien indica Vives-Ferrándiz (2OII: IO2), un objeto polisémico, una imagen privilegiada del desengaño3. El historiador cita, por ejemplo, el auto calderoniano, El gran mercado del mundo, donde aparece Desengaño como personaje alegórico cuya labor es vender espejos. Uno de sus clientes exclama en determinado momento: «Ya veo al cristal del Desengaño que soy polvo, nada y viento» (Vives-Ferrándiz 20II: 48-49). El espejo en el poema de Quevedo refleja un mensaje semejante a través de la imagen de la mujer envejecida en el cristal.

En el poema, el espejo resalta el segundo eje de desengaño identificado por Vives-Ferrándiz: el paso inexorable del tiempo con los resultantes efectos ruinosos sobre la mujer. En los versos siete y ocho, se invoca directamente al tiempo, diciéndonos que éste ha trocado el oro del pelo de la amada en plata. El uso de «ves» en el primer terceto nos recuerda el primer verso del poema de Sor Juana y convierte a la dama en la espectadora de la escena macabra de su propia vejez. La imagen moviliza la mirada y la visualidad del poema, y se convierte en un lienzo con dos «cuadros» superpuestos y

3 Para una discusión más amplia de la imagen del espejo en la poesía amorosa del siglo XXVII, véase mi artículo «Mirroring Desire» (2004). 
una dimensión duplicada del tiempo: la mujer joven de antes y la vieja en el presente. Como en el soneto de Sor Juana, se consigue un sincronismo parecido de imagen visual (retrato implícito) con moraleja verbal. El uso de una metáfora tan privilegiada como la del espejo consigue que todo el poema se convierta en un espectáculo observado a la vez por los lectores. Recordemos que según Emanuel Tesauro y otros teóricos de la temprana edad moderna, la metáfora es la figura más aguda, asociada siempre con la mirada y también con el conocimiento: "perche il mirar con gli occhi, \& il contemplar con l'Intelleto son du especie Analogue di Conoscenza» (Donato 1963: 23). Francisco Herrera también establece la importancia visual de la metáfora (que él llama traslación) en la siguiente cita:

[...] toda la traslación, que es hallada con razón alguna, se llega y acerca a los mismos sentidos, mayormente de los ojos, el cual es agudísimo sentido porque el olor de la cortesanía, la blandura y terneza de la humanidad, el murmorio del mar, y la dulzura de la oración, son deducidas de los demás sentidos. Pero las de los ojos son mucho más agudas y de mayor eficacia y vehemencia, porque ponen casi en presencia del ánimo de las cosas (cit. Gallego Morel I968: 319).

El poema de Quevedo aborda la obsesión con lo visual expresada en Herrera, creando así una inmediatez visual y gráfica, o sea enargeia, que pone ante los ojos de los lectores la doble escena descrita previamente.

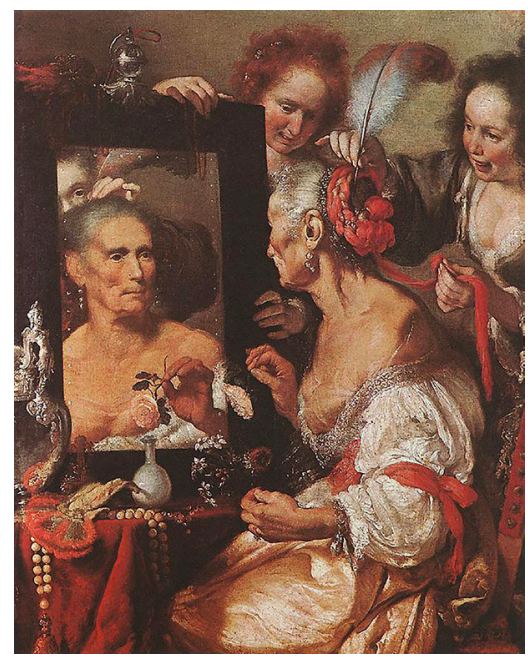

Figura I. Bernardo Strozzi. Vieja mujer en el espejo (I630). 
Otras metáforas de desintegración comunican también una inmediatez asociada con el sentido de la vista. En «Venganza de la edad», el nombre de la dama, Floralba -que pictóricamente connota colores asociados con juventud y belleza en otros poemas-aquí adquiere una dimensión irónica. La mujer se ha convertido en nada menos que un memento mori, una memoria de la muerte; y nos recuerda la representación de figuras femeninas en cuadros de vanitas como, por ejemplo, los cuadros de Bernardo Strozzi [figura I] o especialmente el de Luca Cambiaso [figura 2] donde precisamente vemos a una mujer con un espejo en una mano y una calavera en la otra. Es importante señalar aquí que aunque la asociación de la figura femenina con el tópico de vanitas aparece con cierta frecuencia en la pintura de Italia, Alemania y los Países Bajos; en España, al contrario, está completamente ausente en cuadros de este género. Las vanitas de Luis de Valdés Leal o Antonio de Pereda evitan por completo la figura de la mujer aunque sí reproducen un repertorio de imágenes que corresponde a muchos de los tropos que aparecen una y otra vez en la poesía: velas, relojes, y el mismo espejo, entre otros. Dentro del marco estructural, genérico y aun gráfico del soneto, Quevedo «pinta» un cuadro de vanitas verbal, incorporando a la mujer como la figura central y la personificación del mensaje moral. A diferencia de la pintura donde la moraleja puede ser captada por el espectador de una manera instantánea, el soneto (como toda poesía) requiere una percepción consecutiva del tema. O sea, podemos apreciar el mensaje de un cuadro como el de Cambiaso más o menos sincrónicamente, pero el significado de un poema se despliega en el tiempo cronológico que requieren los ojos del lector para moverse por las catorce líneas del soneto. Como nos dice Pedro Antonio Agudelo, basándose en Lessing, el tiempo es un rasgo propio de la poesía y, a diferencia de la pintura, puede representar el curso de acontecimientos (o el paso del tiempo) de una forma particularmente eficaz y gráfica (2001: 78). En este soneto, como en muchos otros, forma y contenido coinciden temática y estructuralmente. 


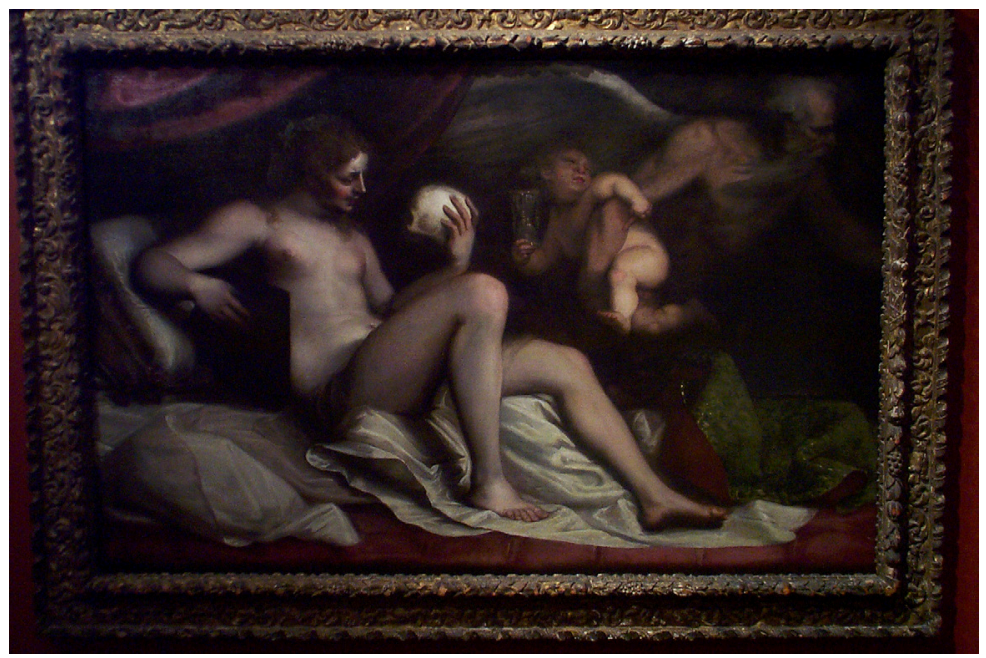

Figura 2. Luca Cambiaso. La vanidad del amor terrenal, @1570 Museo de Arte de Nueva Orleans.

Pasamos ahora a un soneto muy diferente, «Riesgo de celebrar la hermosura de las tontas». Pertenece a la categoría de sonetos satírico-burlescos de Quevedo pero, como el primer poema, invita un análisis más serio relacionado a las tres categorías de vanitas descritas anteriormente.

Sol os llamó mi lengua pecadora y desmintiome a boca llena el cielo;

luz os dije que dábades al suelo y opúsose un candil, que alumbra y llora.

Tan creído tuvistes ser aurora, que amanecer quisistes con desvelo; en vos llamé rubí lo que mi abuelo llamara labio y jeta comedora.

Codicia os puse de vender los dientes diciendo que eran perlas; por ser bellos llamé los rizos minas de oro ardientes;

pero si fueran oro los cabellos, calvo su casco fuera, y diligentes mis dedos os pelaran por vendellos (2003: 476). 
Aunque no hay una alusión clara al acto de mirar o ver, sí encontramos de nuevo el afán de retratar a una mujer, de convertirla en un espectáculo. Como un sinnúmero de poemas amatorios, reproduce la vigilancia y el control de la mujer, reduciéndola a un objeto pero desde la perspectiva del desdén. Comunica justamente este mensaje a través de palabras como desprecio, quejosa, presunción, locura, usura, y depreciada; todas asociadas con el desengaño. El tema del tiempo se implica en el uso insistente del pretérito aludiendo a un pasado cuando se celebraba la belleza de la amada y el contraste con un presente desilusionado. Comprime a lo largo del poema el paso del tiempo, señalando la futilidad de la representación poética en general. El desengaño no yace exclusivamente en el cuerpo envejecido de la mujer sino también en las mentiras perpetradas por las formulas poéticas asociadas con la tradición petrarquista, o sea la misma poesía que Quevedo cultiva. De hecho, de una manera autoconsciente, se citan las imágenes trilladas asociadas con la representación de la belleza femenina en términos de brillantes colores y materiales: luz, sol, aurora, rubí, oro y perlas; pero todas aparecen re-contextualizadas y examinadas desde una perspectiva crítica y desengañada. En el primer cuarteto, la estereotipada asociación de la mujer con el sol y la luz se reniega con el verbo «desmintiome» y con la presencia del «candil que alumbra y llora». La imagen del candil es una imagen que Quevedo usa en textos morales como, por ejemplo, La cuna y la sepultura donde dice: «vela eres; luz de vela es la tuya, que va consumiendo los mismo con que se alimenta y, quanto más aprisa arde, más aprisa te acabarás» (1969: 27). Es además una imagen privilegiada en el repertorio de símbolos que se encuentra en pinturas o emblemas de vanitas [figura 3]. 


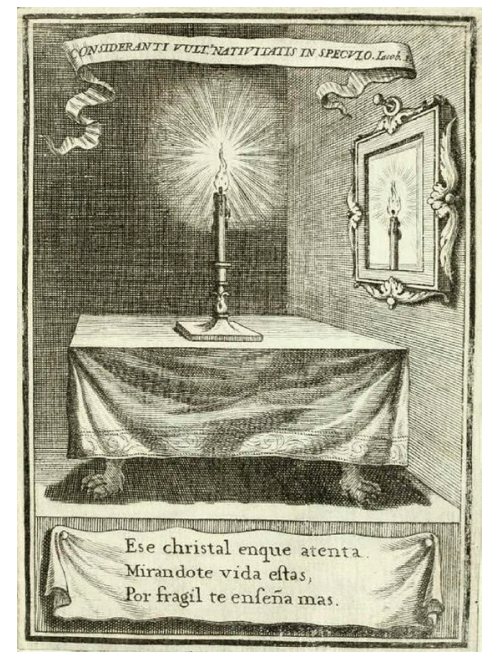

Figura 3. Pedro Rodríguez de Monforte. Descripción de las honras que se hicieron ala Catholica Mgd. de don Phelippe quarto rey de las Españas y del nuevo mundo en el Real convento de la Encarnación (I666).

En la estrofa siguiente, Quevedo continúa jocosamente desmantelando imágenes poéticas gastadas cuando asocia a la mujer con el alba o la Aurora -comparación sugerida en el previo soneto con el nombre de Floralba- pero aquí llevada a un punto absurdo: «Tan creído tuvistes ser aurora,/ que amanecer quisistes con desvelo». Aunque el efecto es uno de humor, al decirnos que esta mujer tonta ha tratado de «amanecer», el poeta otorga movimiento y dinamismo a un tropo poético estático. En los siguientes versos, el estereotípico rubí de la boca se metamorfosea primero en un prosaico «labio» y después en la imagen bestial de una «jeta comedora». Estas descripciones adquieren cierta plasticidad al plasmar dos imágenes - una positiva y otra indigna-ante los ojos del lector. En los tercetos, las metáforas infinitamente reiteradas de los dientes como perlas y el pelo como oro se reifican en la imaginación de la crédula mujer, quien quijotescamente es incapaz de distinguir entre ficción y realidad. Este delirio le lleva a querer vender sus dientes como si fueran perlas verdaderas: «Codicia os puse de vender los dientes, diciendo que eran perlas». Se logra hasta cierto punto una inversión de la enargeia poética en la transformación de metáforas anteriormente idealizadoras en objetos materiales, corruptos o ruines. Con el uso excesivo, estas imágenes han perdido la viveza asociada con la metáfora en el barroco. Se han convertido, como diría Sor Juana, en «falsos silogismos»; y el poeta necesita descontextualizarlas dentro de un marco de desengaño para provocar nuevas imágenes visualmente impactantes. Como ya se ha sugerido, el men- 
saje de desengaño reside no solo en el cuerpo agotado de la mujer sino que implica también al poeta. El mensaje final de desengaño, la verdad de la vanidad burlada que vimos en el primer soneto, se repite autoconscientemente ya que el poeta ha sido burlado de la misma manera. Esto se enfatiza a través de la numerosas alusiones que hace el enunciador poético a sí mismo: «mi lengua pecadora, os dije, en vos llamé»; y en particular en la última estrofa cuando exclama que si la materia poética de su obra fueran verdaderas, él mismo habría participado en la codicia y autoengaño de la mujer, pelando y vendiendo las hebras de oro. La imagen de «calvo su casco fuera» sugiere las calaveras que encontramos en numerosos cuadros de vanitas, una asociación que sin duda los lectores de la época habrían captado de inmediato. El poema funciona entonces a múltiples niveles. Claramente es una parodia de las convenciones asociadas con la poesía petrarquista y, de esa manera, es una crítica amarga de métodos de representación artística. El poeta parece reconocer que el paso del tiempo ha convertido su propia producción poética en una práctica básicamente inútil a la larga. Este poema es una manifestación más de desengaño, con el mismo mensaje y advertencia sobre las trampas de la creación poética que vimos en Sor Juana Inés de la Cruz. En este afán meta-textual, existe además un paralelo con algunos cuadros de vanitas. Vives-Ferrándiz nos dice, por ejemplo, que en un cuadro de Vanitas de Antonio de Pereda, el pintor incluye auto-reflexivamente «un pequeño dibujo de un pintor joven con su paleta y un pincel» que comunica un mensaje parecido al que vemos: la futilidad de la creación artística ante un reconocimiento de la vanidad de la existencia humana (20II: 244).

El título del último texto quevediano que quiero analizar sugiere precisamente la elaboración de un cuadro poético:

Pinta el aquí fue Troya de la hermosura

Rostro de blanca nieve, fondo en grajo; la tizne, presumida de ser ceja;

la piel, que está en un tris de ser pelleja; la plata que se trueca ya en cascajo;

habla casi fregona de estropajo; el aliño, imitado a la corneja; tez que, con pringue y arrebol, semeja clavel almidonado de gargajo.

En las guedejas, vuelto el oro orujo, y ya merecedor de cola el ojo, sin esperar más beso que el del brujo. 
Dos colmillos comidos de gorgojo, una boca con cámaras y pujo, a la que rosa fue vuelven abrojo (2003: 460-6I) ${ }^{4}$.

Este poema se parece al previo en que logra lo que Paul Julian Smith ha llamado «inmediatez gráfica» o chiarezza (1987: 164) en el uso intertextual de imágenes visuales asociadas con la poesía amatoria: el «rostro de nieve» del primer verso, la «plata» del cuarto, el «clavel» en el octavo y la «rosa» del último. Aquí, esas metáforas de color y luz que aludían a la juventud y belleza femeninas se revelan como un trampantojo que esconde la realidad; no son nada más que «engaños coloridos», como diría Sor Juana. Quevedo las transforma en imágenes de decrepitud y en un arsenal de ataque misógino. Como en el poema que acabamos de considerar, el poeta comunica implícitamente que estos consabidos tropos han perdido el carácter eficaz de ornamentación, su enargeia. El tono en este tercer soneto es decididamente más vituperador que los otros dos, y la degradación de la apariencia de la mujer alcanza niveles conceptistas más hiperbólicos. Ha desaparecido el juego temporal de antes y ahora en la representación de la mujer, pero el voyerismo sigue igual. El objeto de la mirada es una vieja repugnante, y los únicos ecos de cualquier tipo de sublimación se encuentran en las fórmulas transformadas de la poesía amatoria, fórmulas - como la mujer-ya también envejecidas. La descripción poética de viejas harapientas tiene una larga tradición, empezando con fuentes latinas en Juvenal y Marcial, siguiendo por la literatura misógina de la edad media y modelos italianos más inmediatos, como Francesco Berni y Agnolo Firenzuola. Parte del ingenio, como en mucha de la poesía de la época, se basa en su imitación ecléctica de diferentes modelos clásicos e italianos. Más allá de la imitación de estas fuentes y del claro ingenio misógino, se puede ver de nuevo en este soneto una manifestación del tema de desengaño y su correspondiente visual, vanitas, tal y como lo define Vives-Ferrándiz. Este soneto va más allá que los dos sonetos previos, sin embargo, en la demolición de las normas aceptadas de la belleza femenina y el cuestionamiento de un sistema de representación que el mismo Quevedo practicaba. Como los paragone que describen la belleza femenina en la poesía petrarquista, la descripción de la mujer en este soneto es selectiva y fragmentaria y, desde un principio, conjura imágenes asociadas con la vista. Por ejemplo, aparecen varias alusiones a los colores como el «rostro de nieve» del primer verso. En esta instancia, al colocar este rostro sobre un «fondo en grajo», la imagen inmediatamente deja de ser una evocación laudatoria. «Fondo», como nos explica Ignacio Arellano se refiere a la fabricación de paños: «designa el campo sobre el que se tejen, bordan o

4 Véase el detallado estudio de este soneto por Ignacio Arellano (I998: 56-65). 
pintan los labores en la tela» (I998: 6I). La negrura de este fondo, que sirve como un tipo de lienzo, se enfatiza con la alusión al grajo, pájaro que tiene alas negras con puntos blancos y que, como los cuervos, se decía que robaba objetos brillantes como monedas. Con esta imagen claro-oscura y complicada, el poeta alude simultáneamente a la fealdad de la mujer, su carácter corrupto y su codicia. Es parte de un cuadro verbal que ofrece al lector una perspectiva particular en la que predominan imágenes de falsificación de lo natural. En el segundo verso, habla del tizne que ciertas mujeres usaban para pintar cejas falsas, de paso sugiriendo una enfermedad venérea ya que la falta de cejas era un síntoma de esta condición. La palabra «pelleja» que aparece en el tercer verso se refiere no solo a la piel envejecida (y hasta animalesca) de la mujer sino que también conlleva el significado de prostituta (Arellano I998: 6I). La plata metafórica de su pelo se ha convertido en cascajos, o sea monedas de poco valor. Apela a lo visual también cuando alude a «la tez de pringue y arrebol», palabras que señalan colores falsos como el maquillaje grasoso que se convierte «clavel almidonado de gargajo». El clavel, otro tropo privilegiado en la poesía amorosa, se transforma en una imagen repugnante y sorprendente que alude, como las imágenes previas, a los afeites que usa esta mujer para esconder su decrepitud. Estas descripciones despectivas y hasta repulsivas continúan hasta las estrofas finales que se concentran en lo que Arellano ha llamado «lo bajo corporal» (2003: I63): «En las guedejas, vuelto el oro orujo,/ y ya merecedor de cola el ojo». El significado escatológico de la palabra «ojo» se hace aún más grotesco con la incorporación de una cola, convirtiendo a la mujer en una creatura demoniaca que sólo un brujo podría desear. El ingenio verbal además se convierte en ingenio visual con la rima que aparece al final de cada verso especialmente en los tercetos: orujo, ojo, brujo, gorg-ojo, pujo y abr-ojo. No es una coincidencia que en tres de los versos, las palabras finales incorporan tanto la mirada como lo escatológico. Estas palabras que conllevan una fuerza gráfica y acústica, impactan al lector y producir en un dinamismo simultáneamente verbal y visual.

La polisemia del discurso poético ofrece un cuadro agudo de putrefacción y muerte que contiene claramente un mensaje moral. La mujer de nuevo se convierte en un esqueleto vivo, su cara una máscara casi desdentada con dos colmillos, llenos de gorgojos o caries. Es otra proto-calavera, que nos recuerda una vez más las que aparecen en múltiples ejemplos de vanitas. Como los sonetos previos, éste comunica una desilusión ontológica con el mundo y las falsas apariencias, demostrando de nuevo que no se puede reducir esta poesía a ejercicios ingeniosos o juegos misóginos. Recordamos las interrogativas que hizo Dámaso Alonso hace muchos años sobre la clasificación de la poesía de Quevedo: «¿Dónde empieza lo burlesco? ¿Dónde termina lo moral satírico? ¿Dónde acaba lo satírico y dónde empieza lo 
filosófico?» (1976: 528). Los tres sonetos estudiados aquí reflejan la indeterminación genérica y la dimensión filosófica a la que Alonso alude. Los brillantes juegos conceptistas encubren el mensaje que vimos en el soneto de Sor Juana y que aparece en los cuadros de vanitas en la confluencia tripartita de mirada, tiempo y verdad. Aunque en la pintura española no se haya permitido una representación pictórica de la desintegración del cuerpo femenino como alegoría del desengaño, la poesía de Quevedo logra una retórica vehementemente visual en su insistente uso de la mirada y metáforas originales y vívidas para describir este cuerpo gastado. El poeta corrosivamente muestra la falsedad de la idealización renacentista de la belleza femenina y la sustituye con lo esperpéntico visual. Los lectores de la época, entrenados en descifrar la iconografía de vanitas en emblemas, dibujos y pinturas, habrían visto en estos poemas representaciones verbales de lo que Antonio Quirós Casado ha llamado «el pathos ibérico», o sea el desengaño (1986: 567).

Concluimos regresando al poema de Sor Juana en el cual, como hemos visto, la invitación al interlocutor a ver el retrato queda frustrada ya que no solo se omite una descripción del cuadro, sino que también se prescinde por completo del repertorio de imágenes asociadas con la tradición petrarquista. Quevedo, por su parte, exagera y transforma esas mismas las metáforas trilladas para provocar nuevas imágenes visuales que terminan comunicando el mismo mensaje ontológico de la monja jerónima. Dentro del marco estructural y gráfico del soneto, los dos poetas -separados por décadas y un océano- exploran las conexión entre palabra e imagen visual contribuyendo a un sistema retórico-visual para comunicar un desengaño existencial y comentar los límites de toda representación artística.

\section{Bibliografía}

Agudelo, Pedro Antonio, «Los ojos de la palabra. La construcción del concepto de écfrasis, de la retórica antigua a la crítica literaria», Lingüística y literatura, 32.60, 200I, pp. 75-92.

Alonso, Dámaso, «El desgarrón afectivo en la poesía de Quevedo», Poesía española: Ensayo de métodos y límites estilísticos, Madrid, Biblioteca Románica Hispánica, 1976, pp. 497-580.

Alonso Veloso, María José, «De amor y venganza en la poesía de Quevedo: perspectivas de la amada envejecida en la tradición del carpe diem», $\mathrm{La}$ Perinola, 16, 2012, pp. 17-46.

Arellano Ayuso, Ignacio, Comentarios a la poesía satírico burlesca de Quevedo, Madrid, Arcos, 1998. 
—. «Introducción», Poesía satírico burlesca de Quevedo. Estudio y anotación filológica de los sonetos, Madrid, Editorial Iberoamericana, 2003.

Avilés, Luis, «Sor Juana en el punto de fuga: la mirada en "Este que ves, engaño colorido"», Bulletin of Hispanic Studies, 77.3, 2000, pp. 4I3-432.

Bergmann, Emilie, «Sor Juana Inés de la Cruz: Dreaming in a Double Voice», Women, Culture and Politics in Latin America: Seminar on Feminism and Culture in Latin America, Berkeley, California University Press, 1992.

Clamurro, William, «Sor Juana Inés de la Cruz Reads Her Portrait», Revista de estudios hispánicos, 20.I, 1986, pp. 27-43.

Cruz, Sor Juana Inés de la, Inundación castálida, ed. Georgina Sabat Rivers. Madrid, Castalia, 1982.

Donato, Eugenio, «Tesauro's Poetics: Through the Looking Glass», MLN, 78 , I963, pp. I5-30.

Gallego, Morell, Antonio, ed., Garcilaso de la Vega y sus comentaristas. Obras completas con comentarios, Biblioteca Románica Hispánica, Madrid, Gredos, 1968.

Quevedo, Francisco, La cuna y la sepultura para el conocimiento propio y desengaño de las cosas agenas, ed. Luisa López Grigera, Madrid, Real Academia Española, 1969.

-. Poesía original completa, ed. José Manuel Blecua. Barcelona, Planeta, I98I.

-. Poesía satírico burlesca de Quevedo. Estudio y anotación filológica de los sonetos, ed. Ignacio Arellano Ayuso, Madrid,Editorial Iberoamericana, 2003.

Quintero, María Cristina, «Mirroring Desire in Early Modern Spanish Poetry: Some Lessons from Painting», Writing for the Eyes in the Spanish Golden Age, ed. Frederick A. de Armas, Lewisburg, Pennsylvania, Bucknell University Press, 2004, pp. 87-Io8.

Quirós Casado, Antonio, «El tema del desengaño», Actas del V Seminario de Historia de la Filosofía española, Salamanca, Ediciones Universidad de Salamanca, 1986, pp. 567-95.

Sabat de Rivers, Georgina, «Sor Juana: la tradición clásica del retrato poético», Estudios de la literatura hispanoamericana. Sor Juana Inés de la Cruz y otros poetas barrocos de la Colonia, Barcelona, PPU, 1992, pp. 79-93.

Sasaki, Betty, «Seizing the Gaze: The Carpe Diem Topos in Sor Juana Inés de la Cruz's "A su retrato"», Caliope: Journal of the Society for Renaissance and Baroque Hispanic Poetry, 3.I, 1997, pp. 5-I7.

Smith, Paul Julian, Quevedo on Parnassus. Allusive Context and Literary Theory in the Love Lyric, Londres, The Modern Humanities Research Association, 1987.

Vives-Ferrándiz Sánchez, Luis, Vanitas: retórica visual de la mirada, Madrid, Encuentro, 20II. 